\title{
Los discursos sobre la lengua mapuche en la producción lexicográfica bilingüe: una primera aproximación glotopolítica al corpus del período 1880-1930
}

\author{
José Miguel Ortiz \\ Investigador independiente, Chile
}

\begin{abstract}
Resumen
El corpus lexicográfico del mapuzugun producido en el periodo 18801930 no ha sido objeto de estudios que lo sitúen en relación con su contexto histórico y lingüístico específico. Este trabajo presenta un primer análisis de los repertorios lexicográficos bilingües producidos en el periodo señalado, correspondiente al final de la resistencia mapuche y el comienzo de la ocupación estatal de los territorios en el sur de las actuales repúblicas de Argentina y Chile. En relación con este contexto histórico se indaga cómo estos instrumentos lingüísticos (Auroux 1992) configuran discursos sobre la lengua que movilizan ciertas ideologías lingüísticas del mapuzugun. Desde una perspectiva glotopolítica (Del Valle 2017) que considera los principios de los estudios críticos del discurso lexicográfico (Chen 2019), se intenta caracterizar la interacción entre los diversos discursos sobre la lengua en el periodo, así como la incidencia de los procesos políticos y militares en el espacio del lenguaje. A partir de algunas características de las obras consideradas, se proponen categorías generales que
\end{abstract}

\footnotetext{
Para correspondencia, dirigirse a: José Miguel Ortiz (kmortizb@gmail.com)
} 
permiten situar y describir el corpus de acuerdo a los discursos sobre la lengua mapuche que se identifican.

Palabras clave: lexicografía, lexicografía bilingüe, glotopolítica, contacto mapuzugun-castellano, mapuzugun.

DISCOURSES ON MAPUZUGUN ON BILINGUAL LEXICOGRAPHICAL REPERTOIRES: A GLOTTOPOLITICAL APPROACH TO THE 1880-1930 CORPUS

Abstract

The lexicographical corpus of the Mapuzugun produced in the period 1880-1930 has not yet been subject to studies that place it in relation to its specific historical and linguistic context. This paper presents a first analysis of the bilingual lexicographical repertoires produced in the aforementioned period, which marks the end of the Mapuche resistance and the beginning of the state occupation of the territories in the south of the current republics of Argentina and Chile. In relation to this historical context we analyze how these linguistic instruments (Auroux 1992) configure discourses on language that mobilize certain linguistic ideologies about the Mapuzugun. From a glottopolitical perspective (Del Valle 2017) that considers the principles of critical studies of lexicographic discourse (Chen 2019), it is characterized the interaction between diverse discourses on language in the period as well as the incidence of political and military processes in the language space. Based on some characteristics of the works reviewed, general categories are proposed that allow locating and describing the corpus according to the discourses on the Mapuche language that are identified.

Keywords: lexicography; bilingual lexicography; glottopolitics; Mapuzugun-Spanish contact; mapuzugun.

Recibido: $14 / 12 / 19$

Aceptado: 21/03/20 


\section{INTRODUCCIÓN ${ }^{2}$}

No pueden comprender el arte de escribir: es considerado por ellos como una especie de magia. Especialmente se asombraron cuando vieron el diccionario (escrito por un misionero jesuita ${ }^{3}$ ) y supieron que a1 consultarlo pude saber palabras de su idioma. Toda tentativa para explicar este misterio fue en vano, porque quedaron estupefactos y apenas pudieron dar crédito a sus sentidos. Uno de los presentes señaló un objeto y me preguntó su nombre indio, lo busqué en el diccionario y le contesté inmediatamente. Quedó incrédulo y asomándose, miraba el libro para ver si podía encontrar alguna semejanza entre el objeto y la palabra impresa. Le indiqué la palabra pero no se conformó con mirar, sino que pasó la mano por el libro para palpar las letras. Un soplo de viento hizo sonar las hojas. Quitó la mano al instante, creyendo que el libro le había hablado bajito en lengua desconocida. Como era la mano izquierda, lo consideró de mal agüero. Se retiró y envolviéndose en su poncho pasó varias horas sumido en un silencio pensativo. (Smith [1855] 1914: 131)

[ella] había aprendido unas pocas palabras de castellano, de modo que con lo poco que sabía yo de mapuche y con la ayuda de mi diccionario de esta lengua, logramos conversar bastante. (Smith [1855] 1914: 122)

¿Cómo podemos esperar que millares de indios aprendan el castellano, si no hay casi ningún chileno que quiera aprender el araucano para servir después de maestro? Por esto, el estudio del araucano tiene una importancia práctica para la República y vale la pena fomentarlo por todos los medios. (Lenz 1895-1897: XV)

En este trabajo se sitúa y describe la producción y circulación de repertorios lexicográficos bilingües del mapuzugun ${ }^{4}$, así como las ideologías y posibles usos que estos sustentan en el periodo que va desde 1880 a 1930,

2 Este trabajo se inscribe en el proyecto FONDECYT Regular 1170419 "Mediación lingüístico-cultural y castellanización en los ámbitos de contacto mapudungun-castellano derivados del proceso de chilenización de la Araucanía: producción lingüística y etnográfica, administración de justicia y escolarización (1880-1930)", (CONICYT, Gobierno de Chile).

3 En la página 142 el viajero confirma que se trata de la obra de Febrés; por la época del viaje (entre 1853 y 1855), es probable que se trate del Diccionario hispano-chileno (Enriquecido de voces i mejorado), edición de Hernández y Astraldi, publicado en Santiago en 1846.

4 Escribo mapuzugun de acuerdo al grafemario Azümchefe a menos que sea utilizado en una cita, en cuyo caso se respeta la ortografía del original. 
correspondiente al final de la resistencia mapuche y el comienzo de la ocupación estatal de los territorios en el sur de las actuales repúblicas de Argentina y Chile. Esta investigación considera dos dimensiones. En primer lugar, a partir de una revisión de diversas fuentes bibliográficas, se definió un corpus de instrumentos lingüísticos lexicográficos del periodo señalado que se presentan en el Anexo. En segundo lugar, se presenta un análisis de este corpus que se propone indagar cómo estos instrumentos lingüísticos, en parte pensados y diseñados para la mediación lingüística, constituyen discursos sobre la lengua que movilizan ciertas ideologías lingüísticas sobre el mapuzugun y su minorización en un periodo en el que parece "no haber espacio para la mediación" (Payàs, Zavala y Samaniego 2012: 444). Se espera con esto ver la incidencia de los procesos políticos y militares en el espacio del lenguaje.

Se sabe que la producción lexicográfica bi o multilingüe antecede a los diccionarios monolingües, ya que esta respondió en su origen la necesidad práctica de intercomprensión de pueblos, culturas y lenguas diferentes (Lara 1997: 21). De ahí que Auroux (1992: 55) postule a los procesos de colonización como un elemento que favoreció la gramatización de distintas lenguas alrededor del mundo: "los contactos lingüísticos se volvieron uno de los elementos determinantes de los saberes lingüísticos codificados" (Auroux 1992: 325). Al decir de Barros Arana y Lenz (1893: 5), "el estudio de lenguas americanas, [ha] iniciado, puede decirse así, el mismo día en que los europeos pisaron el nuevo continente"; existe, entonces, un proceso masivo de gramatización a partir del Renacimiento y desde Europa en el que la gramática y otros instrumentos lingüísticos, como los diccionarios, "se vuelven simultáneamente una técnica pedagógica de aprendizaje de lenguas y un medio para describirlas" (Auroux 1992: 36). Esto explica que la gramatización de las lenguas europeas sea absolutamente contemporánea a la de otros continentes, en particular con las lenguas indígenas de América (Auroux 1992: 40; Payàs 2010: 117). Se entiende, entonces, a la gramatización como "el proceso que conduce a describir e intrumentalizar una lengua en base a dos tecnologías, que son aún hoy los pilares de nuestro saber metalingüístico: la gramática y el diccionario" (Auroux 1992: 65, destacado en el original). En el caso analizado, se trata de una exogramatización (Auroux 1992: 77), en tanto quienes llevan a cabo este proceso no tienen la lengua descrita como materna ni son parte de esa cultura. Son principalmente los misioneros y otros araucanistas quienes

\footnotetext{
Todas las traducciones son propias, a menos que se indique lo contrario.
} 
elaboran estos instrumentos, por lo que el control de la lengua está sujeto a las prácticas metadiscursivas de estos agentes externos.

La gramatización, en definitiva, no solo es relevante por el corpus que produce, sino también porque cambió profundamente la ecología de la comunicación humana y dio a Occidente un medio de conocimiento/ dominación sobre las otras culturas del planeta (Auroux 1992: 9), o, como dice Errington, "hizo de los idiomas objetos de conocimiento, para que sus hablantes pudieran convertirse en sujetos de poder" (2008: 3). Esto señala una asimetría fundamental entre hablantes y lenguas que pueden conocer, hablar y escribir sobre otros, y estos otros y sus lenguas que están destinados a ser conocidos, descubiertos y estudiados (Errington 2008: 55). En este sentido, es importante destacar que la lingüística moderna, en tanto dispositivo epistemológico integrado a la maquinaria colonial, "no se halla en el mundo colonial como podría hallarse en cualquier otro, sino que es parte constitutiva del mismo [...] el suyo es un saber colonial, un saber dedicado a configurar objetos de saber y sujetos de poder" (Ennis y Pfänder 2013: 23, énfasis en el original).El estudio y análisis de los instrumentos lingüísticos, como lo son las obras lexicográficas, en este caso, permiten vislumbrar cómo las intervenciones en el espacio del lenguaje interactúan con los procesos sociales y políticos que los enmarcan. En definitiva, "tanto las gramáticas y los diccionarios como las disposiciones normativas sobre la lengua, los ensayos y las prácticas discursivas participan en la elaboración y puesta en marcha de las políticas lingüísticas". (Arnoux y Luis 2003: 7)

El corpus lexicográfico que se propone ${ }^{6}$ (ver Anexo), considera obras muy disímiles entre sí. Hay muchas que no fueron publicadas como libro o diccionario; de hecho, la mayoría son repertorios lexicográficos no autónomos (Haensch 1997: 60) o que aparecen en obras mixtas (Payàs 2010); esto es, aparecen en un mismo volumen que una gramática, traducciones doctrinales o catecismos. Algunas son recuperaciones de listas de palabras, otras de frases y otras ni siquiera fueron publicadas en Chile o Argentina. Existe asimismo una importante tradición manuscrita misional, por lo que muchas obras ni siquiera fueron publicadas y se perdieron, como la

6 En esta primera aproximación se decidió dejar de lado los trabajos de antroponimia (e.g. Augusta (1907) ¿Cómo se llaman los araucanos?, publicado en Chile) y de toponimia (e.g. Groeber (1926), Toponimia Araucana, publicado en Argentina), aunque no se descarta que puedan entregar información relevante a nuestros objetivos en tanto red de textos interconectados que movilizan discursos sobre la lengua mapuche. De todas maneras, el trabajo de Malvestitti, en este mismo volumen, presenta repertorios lexicográficos que acá se omiten. 
obra de Octaviano de Niza (1888); solo se sabe de ellas por referencias. La existencia de esta tradición manuscrita y el hecho de no ser publicados algunos trabajos permite suponer la existencia de más obras perdidas, por lo que el corpus propuesto no se considera cerrado ni tiene pretensiones de totalidad. Aunque gran parte de estas obras fueron escritas por misioneros, existen también importantes trabajos científicos que tienen una finalidad y un público distintos, lo que da cuenta de un periodo en el que conviven y dialogan, hasta cierto punto, obras misionales y académicas surgidas al alero del 'araucanismo' (Mora y Váquez 2018). A falta de un mejor hiperónimo para este diverso corpus, se referirá en general a este como repertorios lexicográficos. (Haensch 1997: 47)

Un rasgo constitutivo que comparten estos textos es que el "trabajo de la lexicografía bilingüe se fundamenta en la traducción, es decir, en la propuesta de equivalencias" (Olimpio 2009: 85) o sinónimos entre lenguas. En definitiva, los repertorios lexicográficos bilingües son "traducciones condensadas" (Payàs 2010: 125). Además de plantear equivalencias entre dos lenguas y culturas, los repertorios lexicográficos bilingües lo que hacen es fijar y comparar las capacidades de las lenguas implicadas (Payas 2010: 97). Ahora bien, las equivalencias pueden ser planteadas tanto a nivel léxico como a nivel sintagmático, como en el caso de los frasarios y otros instrumentos, tales como los catecismos y confesionarios. Aun así, las equivalencias presentan su propia dificultad cuando en una lengua un lexema se corresponde con una unidad sintagmática más compleja en la otra lengua. Por lo mismo, en un mismo repertorio conviven muchas veces la traducción por equivalencia con notas de carácter enciclopédico, lo que complejiza aún más el corpus a presentar. Pese a todas estas divergencias, el enfoque glotopolítico (Del Valle 2017) y los principios de los estudios críticos del discurso lexicográfico (Chen 2019: 373) permiten considerar que "any lexicographical text [...] is a social act, a product of the socio-political and historical context in which it exists". De esta manera, el análisis que se presenta considera estos instrumentos lingüísticos como discursos; esto es, como la "articulación de un texto y un lugar social" (Arnoux 2006: 15) o, dicho de otro modo, como una práctica lingüística y social inserta en un contexto específico, que debe ser pensada "históricamente" (MeirinhoGuede y Del Valle 2018: 5). Este enfoque, en definitiva, le otorga unidad al corpus seleccionado en tanto una serie diversa de discursos sobre la lengua mapuche en el periodo reduccional.

En el próximo apartado se presenta una propuesta de categorización para situar y describir el corpus seleccionado. Antes de introducir el análisis de las obras consideradas, se hace una necesaria revisión de la producción lexicográfica previa al marco temporal y político señalado; estos antecedentes 
son obras que las publicaciones del periodo consideran, reformulan o reproducen parcialmente. Posterior a esto se presenta ya el análisis del corpus a partir de las categorías propuestas y se exponen algunas conclusiones preliminares de esta primera aproximación.

\section{MISIONEROS, CIENTÍFICOS Y ANTICUARIOS: TRES APROXIMACIONES AL MAPUZUGUN}

En un estudio sobre la producción escrita sobre el mapuzugun, Villena (2017a) propone tres periodos históricos según las diferentes características y funciones que desempeñan los textos. El marco temporal en el que se centra este trabajo, sin embargo, se situaría entre dos de estos: el misional (1606-1894) y el etnográfico (1895-1980). Lo cierto es que esta periodización invisibiliza los distintos intercambios que se dan entre las obras académicas y misionales, en tanto que coexisten y dialogan en este marco temporal. Por lo tanto la diferencia entre estos discursos sobre el mapuzugun no es precisamente temporal, sino que obedece a los públicos para los que se escribe, los usos para los que se proyectan estos instrumentos lingüísticos $\mathrm{y}$, finalmente, la circulación de estos en circuitos diversos. En este trabajo, entonces, se propone una categorización más dinámica que considera estos factores y su relación con el campo intelectual de la época.

La perspectiva glotopolítica (Del Valle 2017) que se adopta en este trabajo implica cuestionar la supuesta neutralidad ideológica y política de las representaciones y prácticas metalingüísticas de los lingüistas. Del mismo modo, al considerar algunos de los principios fundamentales de los estudios críticos del discurso lexicográfico (Chen 2019:362), se asume que "lexicography and its products, dictionaries, are never valuefree, apolitical or asocial. Instead, they are subject to ideology, power, and politics". En definitiva, el análisis que se propone busca relevar el papel político que desempeñan estos instrumentos lingüísticos en el proceso de castellanización de la Araucanía, de retroceso funcional del mapuzugun y de dominación del Estado chileno sobre los mapuche en el periodo señalado.

Una primera división general que se plantea es a partir de la distinción entre obras académicas y misionales. En este caso no se entienden estas como categorías temporales, separadas en el tiempo, sino como dos formas diferentes de pensar la lengua mapuche, coexistentes, asociadas cada una a un objetivo en particular. Evidentemente, como estas obras dialogan, se reeditan y resignifican, la distinción no siempre será precisa, pero permite 
aproximarse al corpus, estableciendo diferencias significativas. Las obras misionales, en primer lugar, responden a una larga tradición con un objetivo y un público particular declarado. Los diferentes instrumentos lingüísticos que se enmarcan en esta tradición tienen un claro objetivo práctico-pedagógico; es decir, son escritas por misioneros principalmente para facilitar el aprendizaje de la lengua mapuche por parte de otros misioneros, con el fin último de evangelizar a la población mapuche en su lengua.

Las obras académicas, por su parte, responden a la tradición de la ciencia lingüística, en tanto discurso totalizante sobre la lengua que, en este caso, busca gestionar la diferencia lingüística dentro de la economía política de la lengua (Ennis 2016). El objetivo de estas obras, por tanto, es el registro de una lengua bajo el supuesto de su pronta desaparición: el saber de la ciencia está relacionado con una posición que no es ni prescriptiva ni intervencionista y que se traduce en la curiosidad arqueológica del otro (Ennis y Pfänder 2013: 141). El público al que se destina este trabajo será un grupo de "intelectuales y hombres de letras que situaron su interés sobre la población indígena" (Mora y Samaniego 2018: 17), los araucanistas. Dentro de este grupo de intelectuales, sin embargo, no deben contarse solo a los lingüistas y antropólogos de la época, sino también a los mismos misioneros, que proveen de importantes materiales para el conocimiento de la lengua mapuche en la época. Los instrumentos agrupados en estas categorías, entonces, dialogan y se enriquecen mutuamente en tanto constituyen distintos discursos eruditos sobre la lengua mapuche.

La diferencia entre las categorías propuestas, misional y académica, ha sido planteada también en otros términos. Por ejemplo, algunos autores señalan que tanto en Perú como en México, y probablemente en otros países latinoamericanos, se manifiesta el interés nacional por lo indígena como antigüedad: "La expectativa de los estudiosos de las antigüedades no era la misma que en la catequesis, es decir, la búsqueda de habilidades para comunicarse con los hablantes y la traducción del mensaje cristiano" (Cifuentes 2002: 71). Si bien los objetivos que señala la autora coinciden a grandes rasgos con los de las categorías propuestas, en este caso se reservará el uso de la categoría de antigüedades para un grupo de obras en particular. "A partir de la segunda mitad del siglo XIX, en efecto, se registra [...] un interés cada vez en aumento por reimprimir artes y vocabularios indígenas redactados en la época colonial" (Guzmán 1998: 42). El interés en el trabajo de reimpresión o reproducción de repertorios lexicográficos, en este caso, perfila una categoría de instrumentos lingüísticos que ya no tienen un objetivo práctico-pedagógico ni de registro, sino que se caracterizan por "el afán coleccionista decimonónico por la producción escrita del Nuevo Mundo 
[...] relacionado con intereses comerciales y sostenido por la demanda de los coleccionistas". (Foz y Payàs 2011: 230)

Finalmente, para hablar de los públicos y usos de los repertorios lexicográficos bilingües, la metalexicografía también ofrece ciertas categorías (e.g. Haensch 1997). Una categoría fundamental es la de direccionalidad, que refiere al orden de las lenguas consideradas:

En el caso de una diccionario lengua extranjera-lengua materna, [el usuario] quiere decodificar (descifrar) un texto para entenderlo completamente o para traducirlo a la lengua materna. Si se sirve de un diccionario lengua materna-lengua extranjera, es porque desea producir un enunciado lingüístico en una lengua que no es la suya o traducir un texto a esta, para lo cual necesita más ayuda que en el proceso inverso. (Haensch 1997: 189)

En la descripción del corpus que se presenta se problematiza la relación entre la direccionalidad y la creación de un público en concreto; así también se revisa brevemente cómo esta misma relación ha sido objeto de ciertos discursos sobre la lengua y sobre los instrumentos lingüísticos que se analizan.

En la sección dedicada al análisis del corpus se presentarán primero los instrumentos catalogados como antigüedades, para resaltar su especificidad. Las categorías misional y académica, sin embargo, se presentarán en un solo apartado y siguiendo un orden cronológico, según el año en que se publican, con el objetivo de evidenciar las relaciones que se establecen entre estos dos discursos sobre la lengua. Como se señaló al final de la sección anterior, antes de presentar el corpus, se hace necesario describir algunos antecedentes lexicográficos, en tanto que siguen vigentes en el marco temporal estudiado.

\section{3. "PARA LOS NUEVOS ESCRIBO, Y NO PARA LOS VIEJOS": ANTECEDENTES LEXICOGRÁFICOS DEL PERIODO}

Vale la pena comenzar con una obra que, aunque publicada en 1765 , es un hipertexto fundamental del que se desprende "un número significativo de epígonos que se publicaron en Chile y en Argentina a lo largo del siglo XIX y hasta ya entrado el siglo XX. Reediciones parciales, revisiones, refundiciones y reciclajes dan cuenta de la supervivencia y la significación de esta obra para una serie de instrumentos lingüísticos incluso más de un siglo 
y medio después" (Malvestitti y Payàs 2015: 283). Se trata, por supuesto, de la obra del misionero jesuita catalán Andrés Febrés, el Arte de la Lengua General del Reyno de Chile, con un diálogo chileno-hispano muy curioso, a que se añade La Doctrina Cristiana, esto es, Rezo, Catecismo, Coplas, Confesionario y Pláticas; lo más en Lengua Chilena y Castellana, y por fin un Vocabulario Hispano-Chileno, y un Calepino Chileno-Hispano más copioso. Esta publicación corresponde a una obra mixta, que tiene como principal fin "el facilitar con sus reglas la práctica de esta Lengua" (Prólogo al estudioso). Por lo mismo, al autor le "pareció muy conveniente añadir un Diálogo Chileno-Hispano, en que estén puestas en práctica [...] para que los que lo leyeren $[\ldots]$ puedan con facilidad hacer composiciones semejantes [...] y también para que teniendo junto en un todo lo preciso para instruirle un nuevo Misionero (pues para los nuevos escribo, y no para los viejos), no tengan que molestarse en buscar más en otra parte" (Prólogo al estudioso). Si bien en este prólogo no se destacan los repertorios lexicográficos, sí queda clara su finalidad misional y la caracterización del libro como un medio tanto para aprender la lengua como para la difusión de la doctrina cristiana, por medio de esta.

La obra original tiene tres secciones lexicográficas; la primera es un "Breve diccionario de algunas palabras más usuales" (pp. 157-181) que aparece en la primera parte de la obra, al final del contenido gramatical y del ejemplo de koyagtun. Es un diccionario ordenado alfabéticamente y con dirección español-mapuzugun que consta de casi mil palabras, como dice al final de este ("Fin de este pequeño Diccionario, niekelu epe kiñe waragka nemül”, p. 181). Según dice el mismo Febrés, "el fin porque se ha compuesto este pequeño Diccionario (fuera de otro mayor, que se pondrá después) solo es para que los Principiantes, mientras estudian el Arte, puedan ejercitarse en conjugar otros verbos y muchos más en hablar (que es lo que más importa) teniendo aquí juntas algunas palabras más frecuentes, usuales y precisas, y cogiéndolas de memoria, a lo cual fácilmente se animarán, por ser tan pocas" (Nota al Breve diccionario..., p. 157). La tercera y cuarta parte, que vienen luego de la doctrina cristiana y rezos, "constituyen la sección lexicográfica de mayor envergadura y abarcan más de la mitad del volumen" (Malvestitti y Payàs 2015: 286). La tercera sección, entre las páginas 195414 , lo constituye el Vocabulario hispano-chileno. Esta lista lexicográfica también está ordenada alfabéticamente, compuesta en doble columna y su dirección es también mapuzugun-español. En las "Advertencias" a este vocabulario, Febrés indica que este procede del Calepino que lo sigue: "las más de las palabras indicadas en el Vocabulario se hallarán explicadas en el Calepino con más claridad" (Febrés 1765: 295). Finalmente, el Calepino mapuzugun-español, la cuarta parte del volumen, se extiende entre las 
páginas 423-711. En cuanto al discurso metalingüístico, es importante notar que en la época de Febrés lo que hemos denominado 'mapuzugun' se le llamaba en ese entonces 'lengua general del Reyno de Chile', como lo indica el título de la obra. De igual forma, los repertorios señalados consideran las opciones 'hispano' y 'chileno', siendo esta última el término para referirse al mapuzugun. La perspectiva histórica permitirá ver que los desplazamientos en la denominación de la lengua mapuche interactúan con la situación política de la población hablante.

Por otro lado, resulta interesante de este volumen que entrega varias pistas, bastante explícitas, sobre la producción lingüística de tradición misional. En primer lugar, destaca su explícita labor práctica-pedagógica y su público misionero. Asimismo, permite ver ciertas prácticas y tradiciones misionales sobre la producción de instrumentos bilingües. Así, aunque quizás no hayan sido pensados para ser publicados, a partir de esta obra se conoce de varios textos que circulaban manuscritos en los conventos y otros espacios misionales. Por ejemplo, previo al Calepino, se indica que este se compuso "principalmente de uno que era (según creo) del Padre Diego Amaya, de Venerable y grata memoria, que fue gran Misionero y Lenguaraz insigne" (Febrés 1765: 422) y "he añadido otras palabras sacadas de otro pequeño Calepino, escrito en Chiloé a los principios de este siglo por el Padre Gaspar López" (Febrés 1765: 423). Ambos Calepinos solo nos han llegado a través de la obra de Febrés y permiten vislumbrar siquiera la tradición manuscrita de los misioneros, que el mismo Febrés en algún sentido estimula al sugerir en su Prólogo al estudioso que su gigantesco libro el estudiante "lo reduzca a un compendio muy breve, que sea solo para su uso, y él solo se lo entienda, aunque sea con otra idea, del mejor modo que él hallase".

Igualmente, los paratextos permiten entrever el método de trabajo del autor. Se sabe que además de elaborar el Calepino a partir de estas dos obras hoy perdidas, Febrés tuvo presente el "Vocabulario del Padre Luis de Valdivia reimpreso en Sevilla y me sirvió no poco de dirección y mucho más el que después tuve en Lima, que imprimió el mismo Padre en dicha ciudad" (1765: 422, Advertencias al Calepino). Igualmente, no solo de textos de otras personas está compuesto el texto, sino que también agregó "otras muchas palabras que iba oyendo en los dos años" que estuvo en Angol. Aun así, no se sabe cuál haya sido el criterio, o incluso si haya habido alguno claro, de selección de las entradas en los repertorios lexicográficos. Otro

\footnotetext{
Resulta importante la incorporación del trabajo de Gaspar López, pues hay muy pocos trabajos que consideren particularmente alguno de los dialectos de la lengua mapuche, sobre todo al hablado en la isla de Chiloé.
} 
punto relevante de esta publicación y sus derivaciones es que se convierte en 1846 en el primer diccionario como tal, al reeditarse la sección lexicográfica que estaba en dirección español-mapuzugun como un libro aparte en versión aumentada y corregida. Se trata del Diccionario hispano-chileno (Enriquecido de voces i mejorado), publicado en Santiago con el patrocinio del gobierno para su uso en las misiones, y fue preparado por el franciscano Antonio Hernández Calzada, edición hecha bajo la inspección del también misionero franciscano Miguel Ángel Astraldi. Por el testimonio de Reuel Smith ([1855] 1914), como se ve en el epígrafe, se puede decir que en su época la cultura escrita entre los mapuche era aún algo ajeno o, al menos, una tecnología cuyo avance fue desigual en distintas partes del territorio. Por lo mismo, este diccionario dirección español-mapuzugun sería útil a quien "desea producir un enunciado lingüístico en una lengua que no es la suya o traducir un texto a esta" (Haensch 1997: 189), es decir, a los hablantes de español o, como en este caso, a los no hablantes de mapuzugun. Es, por tanto, un diccionario activo o de producción (Haensch 1997:58). Pese a las limitaciones de un instrumento como el diccionario en una situación de comunicación real, Smith logra "conversar bastante", según dice, aunque con ayuda del español.

De acuerdo con araucanistas como Tomás Guevara, la reedición que hace Hernández y Astraldi de la obra de Febrés es "un excelente tratado magistral del araucano y ha sido a la verdad el más generalizado en la Arancanía por los misioneros, militares y los indios que han sabido leer" (cit. en Englert 1936: 67, el destacado es mío). Esto claramente señala un uso y un público que supera al destinatario original, ya que incluso son mapuche quienes al parecer hacen uso de este; por lo mismo, no puede ser tan rígida la relación entre la direccionalidad de un diccionario bilingüe, los posibles usos que se hagan de este y los públicos posibles. La direccionalidad, entonces, vale la pena considerarla más como una forma de representación ideológica de la relación entre dos lenguas que un criterio asociado a públicos y usos, como propone Haensch (1997). En definitiva, pese a que cierta direccionalidad suponga un público particular, lo cierto es que el mapuzugun, aunque alguna vez fue lengua general, en aquel entonces era conocida solo por quienes se relacionaban de distintas formas con el pueblo mapuche. Por lo mismo, si la dirección español-mapuzugun supone un público que "desea producir un enunciado lingüístico en una lengua que no es la suya o traducir un texto a esta" (Haensch 1997: 189), lo cierto es que la dirección contraria no estaba destinada a los mapuche que deseasen manifestarse en español. En la mayoría de las traducciones y textos escritos en mapuzugun o formato bilingüe, "los lectores son agentes de la cultura de origen que están situados en la cultura de llegada y operan sobre ella" (Payàs 2010: 95). Asimismo, 
una vez publicados, los textos pueden ser sujetos de diversas apropiaciones que no siempre coinciden con su público y uso original. Como señala Errington (2008: 29), "solo al apropiarse del habla o las lenguas a partir de sus propias prácticas de literacidad, podían 'devolver' una lengua a sus hablantes como el medio del discurso cristiano". Este 'devolver' la lengua en forma escrita, entonces, tiene efectos y usos que superan las intenciones y públicos originales.

Por otro lado, pese a lo que pueda sugerir la tabla del Anexo, la distribución de la direccionalidad de los repertorios lexicográficos bilingües no es tan uniforme como parece. De acuerdo a esta, hasta 1880 no existen repertorios mapuzugun-español. Antes de la fecha señalada, todos los repertorios considerados en este corpus son español-mapuzugun; y posterior a esta fecha, la mayoría de los repertorios siguen la dirección contraria. Sin embargo, en una obra capital como lo es el diccionario bilingüe de Augusta, este justifica en parte la necesidad de este libro precisamente porque a los repertorios lexicográficos anteriores "les falta [...] la parte castellano-araucana, que es un complemento necesario del libro que contiene la explicación de las palabras de la lengua desconocida" (Augusta 1916: III), 'parte' que de acuerdo a la tabla parece ser la norma antes de 1880. Asimismo, Molineaux (2016: 189) plantea que la tendencia anterior a Augusta en materia lexicográfica era la dirección mapuzugun-español, con la excepción de Febrés, lo que es del todo debatible de acuerdo al corpus propuesto. Por lo mismo, conviene analizar este asunto considerando cada caso en particular, su circulación y el tipo de conocimiento sobre la lengua que esta pretende ilustrar.

El Manual o Vocabulario de la lengua Pampay del Estilo Familiar. Para el uso de los jefes y oficiales del ejército, y de las familias a cuyo cargo están los indígenas, publicado en 1879 por Federico Barbará, militar y lenguaraz argentino, se inscribe "en la tradición de los diccionarios bilingües elaborados por misioneros con una finalidad evangelizadora. Pero, a diferencia de estos, tenía como objetivo enseñar la lengua araucana al blanco que debía comunicarse con el indígena por motivos comerciales, militares o laborales" (Kornfeld y Kuguel 1997: 150, el destacado es mío). Resulta interesante atribuir esta obra a la tradición misional cuando el autor es un militar; en este caso se trata de un nuevo actor sobre la lengua mapuche con intenciones comunicativas que exceden al discurso evangelizador. Aunque concordamos con las autoras en que comparte con esta tradición algunas características, lo cierto es que atribuirle esta categoría no sería del todo adecuado. Asimismo, esta publicación permite ver que las reediciones y reformulaciones del texto de Febrés en Chile son anteriores a la campaña de ocupación del territorio mapuche; mientras que las versiones argentinas corresponden a los años finales de la campaña militar encabezada por Julio A. Roca (Malvestitti 
y Payàs 2015). El texto comparte, por tanto, con la tradición misionera su carácter práctico-pedagógico o de mediación, por un lado, y un texto fuente (Febrés), por otro. Se diferencia en que ahora, dado el avance de la 'Campaña del desierto', el público no solo era misionero, sino también militar y comercial. Así, el autor declara que se publica "por el deseo de ser útil a los indígenas y familias a cuyo cargo han sido puestos" y que con "su adopción como intermediario, las personas podrán comprender y hacerse comprender de los indios" (Barbará 1879: 3). El texto, entonces, plantea la posibilidad de comprensión en ambas direcciones, aunque su corpus lexicográfico sea casi completamente unidireccional, español-mapuzugun. La ampliación del público receptor de la obra se condice también con las fuentes de esta. Aunque es evidente la influencia de Febrés, como señalan Malvestitti y Payàs (2015), hay otras fuentes como "varios apuntes inéditos que nos facilitó en 1847, el señor D. Florencio García, vecino de Tapalquen y comerciante en esa época" (Barbará 1879: 4, el destacado es mío), del mismo modo "que sin el concurso del señor Coronel D. Eugenio del Busto, persona muy competente en esta materia, nuestro humilde trabajo sería deficiente" (Barbará 1879: 5, el destacado es mío) y, finalmente, un joven mapuche de nombre Felipe Mariano Rosas.

La sección lexicográfica de la obra corresponde a dos vocabularios; uno ordenado alfabéticamente y que contiene 1816 entradas (pp. 37-91), y otro agrupado por temas (pp. 100-112). El primero de estos consiste en una selección del "Vocabulario Hispano-Chileno" de Febrés (Malvestitti y Payàs 2015), del que no solo toma entradas, sino también su direccionalidad. El último, por su parte, presenta algunas secciones en dirección mapuzugunespañol ("Nombres del vestido y ropa de la muger, joyas, adornos, etc.", "Vestido, ropa y utensilios de los indios" y "Nombres de las piezas del recado o montura"). Son precisamente estas secciones las que presentan un interés particular porque se trata de equivalencias de palabras que en una u otra lengua y cultura no existen como tal. Así, mientras que en las primeras dos secciones se recurre en su mayoría a paráfrasis, en la última se recurre principalmente a préstamos adaptados a la fonología de la lengua receptora, el mapuzugun. Pese a lo apuntado anteriormente con respecto a la direccionalidad en los repertorios lexicográficos, en este caso hay dos puntos a considerar. En primer lugar, como ya se notó, la dirección se hereda de un texto fuente, pero a la vez es seleccionado de un repertorio lexicográfico con una dirección en particular; esto es, la fuente escogida es el "Vocabulario Hispano-Chileno", y no el "Calepino Chileno-Hispano". Se trataría entonces de un diccionario activo o de producción, en tanto está diseñado para quienes desean comunicarse en una lengua que no es la suya, el mapuzugun. En segundo lugar, el público está definido ya desde el título: 
militares y familias que tenían esclavos mapuche. El texto en su totalidad, en parte importante por sus diálogos, permite ver no solo la clara orientación práctica de la obra, sino también la posición social reservada al mapuche.

\section{EL MAPUZUGUN EN EL DISCURSO LEXICOGRÁFICO}

\subsection{LA LEXICOGRAFÍA DE ANTIACUARIO}

Es interesante notar que entre 1880 y 1900 existe un claro declive en la producción lexicográfica misional. Como se señaló anteriormente, en esta época se registra "un interés cada vez en aumento por reimprimir artes y vocabularios indígenas redactados en la época colonial" (Guzmán 1998: 42), que vendrían a llenar ese vacío, aunque con sus particularidades. Estas reediciones corresponden en muchas ocasiones a versiones facsimilares, "quizás las preferidas de los especialistas (historiadores, filólogos, lingüistas), pues en ellas tienen frente a sí el texto [...] tal como salió de la pluma del escritor o por primera vez de la imprenta, con todos sus 'errores', erratas, sabor arcaico y demás aspectos significativos para el consultante especializado" (1998: 42). Este 'sabor arcaico' propio de estas antigüedades no se encuentra solo en las versiones facsimilares, sino también en publicaciones de textos antiguos y encontrados que se publican en revistas científicas sin cambios o revisión alguna.

Destacan en este ámbito las reediciones que hace en Alemania Julius Platzmann de las obras Chili-dugu sirve tractatus linguae chilensis ([1777] 1883), de Havestadt, y el Arte, vocabulario y confesionario de la lengua de Chile ([1606] 1887) de Luis de Valdivia. Resulta del todo llamativo que una lengua como el mapuzugun esté circulando, en formato impreso, en Alemania. La decisión del editor de hacer una reedición facsimilar de estas obras evidentemente no parece responder a un interés misional o prácticopedagógico, sino más bien bibliográfico y, en último término, anticuario. Si bien las reediciones facsimilares son de textos misionales, lo cierto es que su impresión y circulación en Europa cancela sus posibilidades de funcionamiento práctico. El caso de la obra de Havestadt es quizás más llamativo que el de Valdivia, pese a la antigüedad de esta última; reeditar el Chili-dugu supone un público bastante reducido, considerando que el siglo XVIII marca el fin del latín como lengua de la cultura y se da paso a las lenguas nacionales como forma natural de escritura. Una obra escrita en 
latín sobre una lengua indígena americana e impresa en Alemania no podía sino responder a un público coleccionista, ligado a la bibliografía anticuaria (Foz y Payàs 2011). Por el momento no se tienen datos que permitan saber si estas obras circularon en Chile o Argentina ni en qué circuitos, académicos o misionales, pero estas reediciones parecen indicar decididamente la entrada del mapuzugun a otros espacios.

Por otra parte, a partir de 1906 Schüller publicará "El Vocabulario Araucano de 1642-1643. Con notas críticas i algunas adiciones a las bibliografías de la lengua mapuche", que aparece en tres entregas hasta 1907 en los Anales de la Universidad de Chile. El texto, además del vocabulario en sí, contiene una detallada guía bibliográfica sobre los mapuche y el mapuzugun hasta 1907. Esta publicación se enmarca claramente dentro del trabajo anticuario, ya que el autor declara que esta es una "copia fiel" de la edición original de la obra y ni siquiera enmienda errores. De la misma manera, publica el vocabulario con el mismo sistema de escritura de la época, sin considerar las convenciones de la época, lo que de todas maneras lo deja al margen de la tradición araucanística clásica ${ }^{8}$. Aun así, es posible ver cierta actualización metadiscursiva: el original, en latín, se refiere a 'De Chilensium Lingua', mientras que la publicación de Schüller nombra a esta lengua 'araucano' en el título e 'idioma mapuche' en el prólogo. Definitivamente, ya en el 1900 el mapuzugun había dejado de ser 'la lengua de Chile', lo que sin duda se debe a la instalación definitiva del funcionamiento estato-nacional en el otrora territorio mapuche. El texto presenta un repertorio lexicográfico que, de acuerdo con el autor, sería el segundo documento impreso sobre la lengua mapuche, después de Valdivia; en definitiva, una 'antigüedad'. Por lo mismo, "debe ser multiplicado en letras de molde i puesto así al fácil alcance de todos aquellos que tienen interés por el estudio del idioma de nuestros araucanos" (Schüller 1906: 20, el destacado es mío). El repertorio, que el autor llama glosario, apareció originalmente en 1647 en la obra del poeta holandés Gaspar van Baerle. Contiene una primera sección de 515 entradas en mapuzugun con su equivalente en latín a doble columna, por lo que su dirección es mapuzugun-latín, y no está ordenada alfabéticamente. Una segunda sección tiene 296 entradas, del mismo modo y dirección que la primera. Contiene, igualmente, algunas secciones temáticas específicas, como los números y otra que introduce algunas preguntas, por lo que el repertorio no es solo de ítems léxicos aislados, sino que también hay

8 Como se verá en la sección siguiente, dos destacados araucanistas llegan a un 'acuerdo para la uniformidad' con respecto a la escritura del mapuzugun en 1903. 
equivalencias sintagmáticas. Le sigue luego un repertorio de características similares, pero cambia el latín por el inglés, con 473 entradas. Finaliza con 488 entradas a tres columnas mapuzugun-alemán-español, que incluye indistintamente palabras, frases y preguntas. Las lenguas implicadas en la traducción del repertorio lexicográfico claramente hacen difícil pensar que el texto haya cumplido algún objetivo práctico, más allá de ser un insumo para el trabajo académico.

En 1914 aparece un texto similar en varios aspectos al trabajo de Schüller (1906-7), aunque sin las notas bibliográficas críticas. Se trata de "Un texto y un vocabulario en dialecto pehuenche de fines del siglo XVIII", publicado en la Revista de la Universidad de Buenos Aires por Félix Outes. A diferencia del anterior, sin embargo, en este caso algunos comentarios se refieren al texto e indican y enmiendan en nota al pie algunos errores, aunque Outes confiesa: "omití verificar en el momento oportuno ciertas operaciones imprescindibles de buena crítica" (Outes 1914: 68). El texto y el vocabulario fueron encontrados en el Departamento de manuscritos del Museo Británico y aparece, de hecho, en algunas bibliografías, como la de Schüller (1907). Aunque el manuscrito "no lleva fecha alguna, como tampoco ofrece la más mínima indicación de la cual pudiera inferirse cuándo, dónde y por quién fue redactado" (Outes 1914: 69), por el motivo anteriormente señalado Outes decide publicarlo "fuere cual fuere su valor" (1914: 68). Según el examen del original, quien lo publica afirma que la autoría corresponde a dos personas, una para el diálogo y otra para el vocabulario. Outes concluye, entonces, que el posible autor del diálogo sería un intérprete del cacique Carilegu y que Antonio Pineda, guardamarina y botánico a bordo de la expedición Malaspina, amplió esa información con una breve lista de voces. Esta información permite situar el texto a finales del 1700, probablemente en 1790. (Outes 1914: 70-71)

El texto y el vocabulario, según Outes, tienen valor para los especialistas (lingüistas) "para fijar mejor los matices, y seguir las transformaciones experimentadas por una de las formas dialectales del araucano" (Outes 1914: 71, el destacado es mío). Nuevamente se confirma la persistencia del nombre de la lengua en este periodo, lo que parece indicar que ha operado una reducción del ámbito en la representación del mapuzugun, que por una parte puede considerarse que responde a una realidad geográfica; pero también a una proyección y a una operación de reducción representacional mayor. En el mismo sentido, resulta interesante que, al igual que el trabajo de Cañas Pinochet (1911) que se revisará en la próxima sección, este es uno de los pocos vocabularios que presta atención a un dialecto en específico, lo que reviste sin duda un interés mucho más académico que práctico-pedagógico. La dirección del repertorio lexicográfico es mapuzugun-español, dirección 
que parece ser más frecuente en los trabajos anticuarios y académicos que en los misionales. Recoge palabras básicas de la lengua, como los números, algunos elementos de la naturaleza, colores, etc. Contiene un total de 65 entradas que se definen por equivalencia en doble columna y otras tres que se definen más enciclopédicamente en un párrafo aparte.

\section{2. "No NOS HEMOS LIMITADO A BUSCAR LAS PALABRAS NECESARIAS PARA EXPRESAR LAS DOCTRINAS DE NUESTRA SANTA RELIGIÓN": LOS DISCURSOS LEXICOGRÁFICOS MISIONALES Y CIENTÍFICOS}

El primer repertorio lexicográfico bilingüe que se encuentra posterior a 1880 es una reedición del "Calepino Chileno-Hispano" de Febrés, a cargo de Juan Mariano Larsen en Argentina, 1882. Resulta interesante que la selección del texto que se reedita implica también la selección de una direccionalidad en particular y de un texto que no había sido reeditado hasta entonces. Es de notar que hasta las obras de Augusta (1903), la mayoría de la producción lexicográfica bilingüe se concentra en el lado este de la Cordillera. Llama igualmente la atención el nombre del libro: "Diccionario Araucano Español, o sea, Calepino chileno-hispano", donde ahora calepino pasa a ser diccionario y chileno pasa a ser araucano. Este es el ejemplo más temprano del corpus en que la lengua recibe este nombre, que coincide ya con la proximidad de la instalación militar en el territorio mapuche por parte de los Estados argentino y chileno. Si bien el texto original es claramente misional, el editor, en "una muy breve nota introductoria, señala su posible utilidad para los estudiosos" (Malvestitti y Payàs 2015: 294), y en una nota periodística señala que con la edición de un vocabulario araucano, "nuestros militares podrán completarlo, ahorrándose el trabajo de apuntar lo que ya está impreso" (cit. en Malvestitti y Payàs 2015: 294). De la misma manera, Larsen publicará dos años después la Gramática Araucana, que incluye el "Breve diccionario de algunas palabras mas usuales", texto que ya se comentó al presentar la obra de Febrés. Esta reedición se trata de una "obra de alcances obviamente científicos, remite en su enjundioso prólogo a estudios de otros autores, establece análisis comparativos con otras lenguas, y plantea hipótesis sobre las diversas formas dialectales de la lengua araucana" (Malvestitti y Payàs 2015: 295).

Los primeros repertorios lexicográficos bilingües que se encuentran posterior a 1880, entonces, fueron publicados en Argentina y corresponden a obras que se pueden categorizar, según lo revisado, como académicas. Al tratarse de reediciones, conservan solo en parte su objetivo práctico asociado a lo misional, ya que circulan ahora en otros circuitos, por lo que sus receptores 
se amplían al igual que sus objetivos. Llama la atención igualmente que en esta época varios repertorios están escritos por o destinados a militares, que es un rasgo que no parece ser explícito en Chile, pero que parece indicar el valor del mapuzugun como una lengua de comunicación en estos espacios de conflicto.

Recién en 1888 se vuelve a encontrar una obra producida en Chile: se trata del "Breve Metodo della Lingua Araucana y Dizionario Italo-Araucano e Viceversa", del capuchino italiano Octaviano de Niza, cuyo manuscrito se perdió en el incendio del Convento Capuchino de la ciudad de Valdivia, en 1928 (Noggler 1973: 78, cit. en Salas 1985: 205). Este resulta ser el primer diccionario bidireccional, lo que da cuenta de un desarrollo importante en la lexicografía bilingüe misional. Por su carácter de manuscrito perdido, se le puede situar igualmente en la tradición manuscrita misional, lo que determina su circulación y uso práctico-pedagógico. No se han encontrado mayores referencias a este texto, salvo que fue realizado sobre la base del vocabulario de Valdivia, aunque por el momento no está claro a qué edición de este correspondería.

Por la misma época, en Argentina, se reedita el Pequeño Manual del misionero para evangelizar a los indios fronterizos ([1876] 1900), del lazarista italiano Pablo Emiliano Savino. Este libro originalmente es un "texto bilingüe a dos columnas en forma de interrogatorio que contiene: 'Catecismo menor', 'Confesionario Indio', 'Repertorio de frases usuales y exhortación', 'Direcciones necesarias sobre la escritura, pronunciación y acentuación del idioma indio'; 'Del acento' (Nicoletti y Malvestitti 2008: 97) y fue producido para la evangelización de la gente del logko Coliqueo en Los Toldos, provincia de Buenos Aires (Malvestitti 2010: 58). Se trata, como parte importante de la producción lexicográfica de la época, de una reelaboración libre de la obra de Febrés. La reedición del 1900, a cargo de la congregación salesiana, contiene además un repertorio lexicográfico, el "Pequeño Diccionario de las voces que se hallan en este manual hecho por un Padre Salesiano", que Malvestitti (2010) atribuye al italiano Domenico Milanesio. Su circulación se contextualiza en las campañas militares de ocupación de Pampa y Patagonia por parte del Estado argentino. Es importante notar que la obra del lazarista Savino y su reedición salesiana no incluye oraciones en mapuzungun, porque al lazarista le parecía más conveniente "que los indios fronterizos aprendan el Rezo en castellano que en su propio idioma" (Savino 1876: 34). A partir del título del repertorio en cuestión, se puede suponer que la dirección de este pequeño diccionario sea mapuzugun-español. Asimismo, se puede ver que en este caso el uso del mapuzugun se daba solo en ciertos contextos especíicos, como la confesión, pero se proyectaba ya una paulatina castellanización a partir del aprendizaje de rezos y quizás otras prácticas misionales de alfabetización. 
En esta época comienza su trabajo Félix de Augusta, quien "a partir de 1901, ocupó diversos cargos administrativos y directivos en la Misión de la Araucanía" (Salas 1985: 199). Desde esta posición fue preparando materiales didácticos destinados a facilitar el aprendizaje de la lengua mapuche y servir de complemento a los cursos que él dictaba acompañado de sus informantes para sus compañeros religiosos (Salas 1985: 209). La producción en mapuzugun de Augusta es bastante amplia, pero destacan tres obras fundamentales: su gramática (1903a), su colección de textos (1910) y su diccionario (1916). Estas obras, en definitiva, dan cuenta de la concepción que tenía Augusta del proceso de aprendizaje y enseñanza de lenguas. Así, para el aprendizaje se debía disponer, en primer lugar, de una exposición de la estructura gramatical, organizada en lecciones cortas con abundante ejemplificación y que van aumentando su complejidad. De ahí, entonces, la publicación de la gramática. Se necesitaba, igualmente, un instrumento que considerara las unidades léxicas, raíces y afijos, lo que justifica la publicación del diccionario. Finalmente, como Augusta "creía en la eficacia de la traducción como mecanismo de práctica y ejercicio para las estructuras aprendidas y la adquisición de vocabulario" (Salas 1985: 209), era necesaria la colección de textos Lecturas Araucanas. De esta manera, estas tres obras fundamentales se complementan como parte de un programa pedagógico "obviamente originado en la práctica habitual en el aprendizaje y enseñanza del latín y el griego" (Salas 1985: 209). Del mismo modo, se puede ver que el uso del nombre 'araucano' para referirse a la lengua mapuche estaba decididamente instalado, sobre todo desde la Misión de la Araucanía.

La primera de estas obras, la Gramática Araucana (1903a), contiene dos repertorios lexicográficos que evidencian el conocimiento araucanista del autor de las discusiones y producciones académicas asociadas al mapuzugun. Salas (1985: 199) señala que desde esta publicación, Augusta "fue reconocido por los araucanistas chilenos como el mejor conocedor de la lengua y la cultura de los mapuches contemporáneos". Se puede decir, en definitiva, que esta obra y las demás de la trilogía de Augusta se encuentran a medio camino entre ambas categorías propuestas: misional y académica. Lo misional es innegable desde el "Prefacio" de la gramática, donde señala que ha sido compuesta "por orden del M. R. P. Burcardo M. de Röttingen, Prefecto Apostólico de las Misiones Capuchinas de la Araucanía, y tiene por objeto iniciar en el aprendizaje del idioma mapuche a los Misioneros que se ocupan en la conversión de los indios" (Augusta 1903a: III). Lo académico en parte se manifiesta por su posición crítica frente a los trabajos misionales anteriores (i.e. Valdivia, Havestadt y Febrés), lo que si bien también es parte de su enfoque práctico-pedagógico al señalar que "es punto menos que 
imposible adquirir por ellas un conocimiento práctico del idioma indígena" (Augusta 1903a: III), hace eco también del discurso de Lenz, que trae consigo el paradigma de la lingüística moderna (Altschul 2012: 43). Este señalaba que no existían "documentos escritos en el idioma que puedan considerarse como lejítimo araucano" (Lenz 1895-97: VII, el destacado es mío) y que para comenzar un estudio científico sobre la lengua mapuche era "indispensable prescindir por un momento de todo lo que nos enseñan las obras de los misioneros i recoger materiales orijinales" (Lenz 1895-97: VIII). Asimismo, Augusta señala en su colección de textos Lecturas Araucanas que el motivo de su publicación era "poner en manos de los P.P. Misioneros unos Textos escritos en legítimo araucano, en los cuales pudieran encontrar, para el más fácil y correcto aprendizaje de dicho idioma, la aplicación práctica de las reglas de la gramática". (Augusta 1910: V, el destacado es mío)

Sumado a lo anterior, como evidencia del diálogo entre las esferas misionales y académicas dentro del araucanismo de la época, ya para la fecha de la publicación de la Gramática... (1903a), existía cierta voluntad por uniformar criterios ya no solo en cuanto al nombre de la lengua, sino a la escritura de la misma:

Es de lamentar que en cada publicación hecha en idioma araucano, los autores hayan servido de otros caracteres para expresar ciertos sonidos propios del lenguaje araucano, y, con el objeto de establecer más uniformidad, me puse de acuerdo con Rodolfo Lenz, cuyo método me parece ser el más adecuado para reproducir sonidos propios del idioma. (Augusta 1903b:IX, el destacado es mío)

Con este criterio de uniformidad para los textos se puede proyectar un uso práctico mucho más extendido y normado. Habría que preguntarse, claramente, si esta uniformidad favorecería a los hablantes de mapuzugun $\mathrm{o}$, por el contrario, a académicos y misioneros, puesto que estos últimos son los que producen y leen mayoritariamente en esta lengua y, por otro lado, la alfabetización a la población mapuche en su propia lengua no tiene antecedentes significativos. Este estándar de la escritura es el que utiliza buena parte del araucanismo en Chile por lo que, irremediablemente, quienes no observan esta norma quedan fuera de esta tradición y de las prácticas letradas que sostenían (misionales y de otra índole).

De igual manera, el reparo de Augusta con respecto a las obras misionales anteriores se da también por otros motivos. En primer lugar, por su antigüedad no corresponden al mapuche contemporáneo, son poco descriptivas, proponen malos ejemplos y fueron preparadas con el modelo de análisis latino (Salas 1985: 206). Este último punto es sumamente significativo con respecto a la obra de Augusta, donde se abandona el modelo 
latino nebrisense por "violentar el idioma" y se utiliza un modelo adecuado a la ciencia moderna, personificado en este caso por Bello: "Por eso hemos abandonado ese método, y ni siquiera hemos adoptado la terminología latina para la denominación de los tiempos y demás formas gramaticales. La reputada obra del famoso gramático venezolano, Dn. Andrés Bello, nos ha servido para ello, y en lo que ella no nos ha bastado, nos hemos servido de expresiones de nuestra propia invención" (Augusta 1903a: IV). El academicismo de Augusta, sin embargo, no es tal que le permita perder de vista sus objetivos práctico-pedagógicos y misioneros, por lo que contrario a Lenz y su énfasis en la variación dialectal, este declara: "No hemos hecho estudios detenidos sobre los dialectos indígenas; pero por el contacto que hemos tenido con indios de distintas comarcas, algunas de ellas bastante lejanas entre sí, creemos poder afirmar que las diferencias de esos dialectos se reducen solo a la diversa pronunciación de algunos sonidos consonantes, a1 cambio de ciertas letras y a alguna alteración en el significado de varias palabras y en la formación de las transiciones". (1903a: VIII)

La Gramática Araucana está estructurada de tal forma que después de leer las lecciones de la I y la II parte se pudiesen leer los textos de la III parte, con ayuda de los vocabularios que aparecen en la IV parte. Estos vocabularios son dos, uno en dirección español-mapuzugun y otro en dirección mapuzugun-español. Como señala el autor: "Nuestra Gramática, va acompañada de un vocabulario español-araucano, que es el mismo de la Gramática de Febrés, con pocas variantes en el texto castellano, pero con notables diferencias en el araucano; en otro vocabulario araucano-español, que ponemos a continuación, damos lugar preferente a los verbos simples más usados de la lengua araucana" (1903a: VIII, el destacado es mío). Llama la atención que pese a todo lo moderno de Augusta, el referente lexicográfico siga siendo Febrés; claramente habrá que esperar su publicación de 1916 para ver mayores avances en este aspecto. Finalmente, otro elemento que sitúa a Augusta como araucanista, es cierta visión que ve lo mapuche como condenado a la desaparición: "Es fácil prever que el idioma indígena apenas se hablará en Chile de aquí a unos cien años; la interesante y heroica raza araucana está ya por desaparecer" (VIII). Del mismo modo, la circulación de la obra de Augusta excede el misional; Mora y Vásquez (2018: 53) señalan que Lenz envía una copia de esta gramática a quien fue jefe de la sección de antropología en el Museo de la Plata entre 1897 y 1930, Lehmann-Nitsche, y que posteriormente (1916 y 1919), Augusta y este último intercambian cartas sobre temas araucanistas.

De aquí en adelante hay un claro predominio de las obras académicas por sobre las misionales. Un claro ejemplo de esto es Estudios de la lengua veliche, publicada en 1911 por Alejandro Cañas Pinochet. Resulta 
interesante este texto, puesto que se plantea desde un dialecto en particular del mapuzugun, a diferencia de la mayoría que, al menos nominalmente, se referían a la lengua general. Igualmente, queda claro su carácter académico en tanto no es solo un repertorio lexicográfico, sino que incluye también un amplio tratado sobre su "probable origen", comparaciones con otras lenguas y algunos textos breves en varias lenguas. Del mismo modo, acorde a la retórica de la aflicción que caracteriza al araucanismo, el autor señala que "tras no largos años, la raza primitiva que pobló el Archipiélago habrá desaparecido y su lengua con ella, para figurar aquella en el panteón de la historia" (Cañas 1911: 143). Es interesante notar que el avance de la "cultura" y la civilización en la Araucanía, y la consecuente minorización del mapuzugun, se asumen como un a priori y una etapa inevitable en el desarrollo de la nación. No existe, por tanto, un cuestionamiento a los eventos históricos específicos que han impulsado la pauperización material y lingüística del pueblo mapuche. "No es que deba evitarse su desaparición, que sigue pareciendo forzosamente signada por la historia, sino que la misma debe dilatarse hasta que la ciencia como registro totalizante pueda incluirla en su archivo". (Ennis y Pfänder 2013: 119)

Este texto, aunque presente un repertorio lexicográfico como un apartado entre las páginas 247-330, incluye información léxica a lo largo de toda la exposición como una forma de demostrar ciertas hipótesis que el autor va planteando. En algunos casos se define por equivalencia, mientras que en no pocos casos se hace enciclopédicamente. El "Vocabulario de la lengua Veliche", señala en su "Advertencia necesaria" como justificación para este trabajo, "el interés de recoger los últimos elementos de una lengua que se extinguía para siempre" (Cañas 1911: 244). Del mismo modo, señala el aporte de su informante clave, Juan Elías Necul, autor de los collaq que aparecen en el texto. El vocabulario trata explícitamente sobre la botánica, la zoología y la "etnografía" de los habitantes de la isla de Chiloé, en dirección mapuzugun-español. Incluye del mismo modo algunas formas verbales y muchas y largas definiciones enciclopédicas, asociadas al carácter etnográfico de la obra. No está en estricto orden alfabético, salvo la primera letra.

Posterior a esta obra, en Argentina, aparece en 1915 la obra Etimología Araucana. Idiomas comparados de la Patagonia. Lecturas y frasario araucano, del salesiano Domenico Milanesio. Si bien puede plantearse como misional por el perfil del autor, hay que considerar también que a estas alturas estas obras dialogan necesariamente con los trabajos académicos. Asimismo, en esta fecha el autor ya estaba retirado de la vida misional, por lo que esta obra tardía puede tener otra finalidad; lamentablemente, no se ha tenido acceso a esta fuente, por lo que no se han podido revisar los paratextos que podrían dar más luces con respecto a ese punto. La información con la que 
se cuenta en estos momentos sobre esta publicación proviene principalmente de dos estudios, Nicoletti y Malvestitti (2008) y Malvestitti (2010). La obra está divida en tres secciones, de las cuales solo la primera reviste interés para esta presentación, en tanto en esta aparece el repertorio léxico bilingüe. Este está compuesto por "691 entradas léxicas [que] incluyen lexemas comunes, antropónimos e incluso palabras de origen no mapuche (quechua, español, tehuelche septentrional), y, como señalan investigaciones previas, el texto es de valor sumamente dudoso, ya que presenta numerosas etimologías erróneas o disparatadas" (Nicoletti y Malvestitti 2008: 108). Aun así, según palabras del mismo autor, se sabe que esta obra es "un pequeño diccionario [...] no es trabajo mío, sino la mayor parte compilado de otros misioneros de Chile. Yo no tuve otra cosa que hacer que juntar algunos términos que no estaban para completarlos" ("Carta de Milanesio, cit. en Nicoletti y Malvestitti 2008: 108). Incluso en esta época y para esta obra, Febrés continúa siendo una fuente recurrente. Además de esta sucinta descripción, carezco de datos que permitan determinar su circulación y recepción, pero resulta claro que a esta altura el término 'araucano' para referirse a la lengua mapuche estaba ya asentado a ambos lados de la cordillera. Del mismo modo, esta obra es otro claro ejemplo de la superposición entre obras académicas y misionales.

Por esa época, concretamente en 1916, Augusta publica en dos tomos, uno para cada dirección, el célebre Diccionario Araucano-Español y EspañolAraucano. La obra cuenta con 5127 artículos para el primer tomo y 6691 para el segundo. Cada uno señala "categoría gramatical de la entrada, explicación semántica adicional, usualmente entre paréntesis, equivalentes mapuches para las diversas acepciones y usos de la entrada, muchas veces con su indicación geográfica [...], ejemplos de uso y referencias a la Gramática Araucana" (Salas 1985: 262). Es, por lo mismo, la cúspide de la labor lexicográfica de la época y conjuga de buena manera el aspecto misional con las discusiones araucanistas, lo que se manifiesta claramente en el prólogo: "Nuestro intento, que es idéntico con el de la Prefectura Apostólica a cuyas órdenes estamos, no ha sido hacer un Diccionario histórico [como proponía Lenz ${ }^{9}$, sino uno del araucano moderno, que sirva a los Misioneros para poder

9 "Es evidente que la filología araucana con estas grandes obras de Fray Félix todavía no ha llegado al término de sus tareas. Es de esperar que otros misioneros se pongan al trabajo de completar el diccionario con las voces corrientes en otras regiones y que estas listas se publiquen oportunamente. Entonces pronto llegaría el tiempo para confeccionar la obra definitiva: un gran diccionario histórico y comparado que mostrará en tipo grande todas las voces primitivas con indicación de lugar y fecha de la documentación, y en tipo menor todas las composiciones y derivaciones modernas, necesarias para el manejo práctico del idioma". (Lenz 1917: 134) 
hablar a los indígenas en un lenguaje correcto, bien inteligible para ellos" (Augusta 1916: IV). En esta cita se puede ver que, aunque muy consciente de las preocupaciones araucanistas, se prefiere el aspecto práctico-pedagógico de la labor misional, pero va también un poco más allá: "ciertamente no nos hemos limitado a buscar las palabras necesarias para expresar las doctrinas de nuestra Santa Religión". (1916: IV)

La publicación se justifica con argumentos similares a los de la Gramática, como una forma de actualizar los instrumentos lingüísticos. Así, por ejemplo, al señalar las fuentes de su labor lexicográfica, recurre evidentemente a toda la tradición misional, desde Valdivia hasta la publicación de Havestadt. En el caso de Febrés, señala que revisó tanto la edición original como la reedición de Larsen (1916: VIII). Todas estas obras, señala, "son ciertamente de mucho mérito; pero como las costumbres de los indios y todo su mundo de ideas ha cambiado enteramente por el contacto con la gente civilizada y las nuevas condiciones de vida en que se encuentran: muchas de las explicaciones que dan aquellos Vocabularios, no eran ya inteligibles al intérprete ni lo son a los indios modernos en general. [...] Además abundan, especialmente en Febrés, las palabras-raíces y los términos raros, pero escasean los verbos compuestos con sus múltiples acepciones tan indispensables para la conversación" (1916: VIII, el destacado es mío). El criterio de admisibilidad, entonces, era que estas palabras estuviesen en uso: "podemos garantizar que las palabras que figuran en nuestra obra las hemos oído emplear por los indígenas" (1916: III). Por lo mismo, publicaciones como sus propias Lecturas Araucanas y los Estudios Araucanos de Lenz, también son parte del corpus del que se extraen entradas para el volumen mapuzugun-español. Bajo este mismo principio, el de la relevancia del uso contemporáneo, el diccionario tampoco contempla etimologías, topónimos, onomástica, ni información enciclopédica (salvo en los términos que no poseen equivalentes directos). Por otro lado, es sumamente interesante el trabajo que se hace con los informantes nativos ${ }^{10}$, en tanto estos son, en último término, el punto de referencia para la obra: "en el nuevo Diccionario intencionalmente no hemos reproducido de los autores antiguos sino los vocablos que están todavía en uso hoy día o que, por lo menos, eran conocidos por nuestros intérpretes araucanos". (1916: IV, el destacado es mío)

10 El trabajo con los informantes nativos y la información que proporciona el diccionario sobre esto es muy interesante para revisar el tema de la alfabetización y las competencias en castellano en la población mapuche. No me remitiré a ellas en esta ocasión porque creo que merecen un análisis por sí mismas. 
El diccionario en sus dos tomos, más allá de su finalidad misional, demuestra una relación con las ciencias de la época en más de un aspecto. Así, por ejemplo, para los nombres de plantas "el profesor de Botánica de la Universidad del Estado, Dr. don Fr. Johow, tuvo la amabilidad, que debidamente le agradecemos, de clasificar todas estas plantas y de comunicarnos sus nombres científicos" (1916: IX). Por otra parte, para la formulación del segundo tomo, se considera un material lexicográfico que ya tenía cierta tradición y autoridad: "nos hemos valido del Diccionario de la Academia Española [suponemos, con Villena (2017b:XVI), que es las $13^{\circ}$ edición de 1899], entresacando lo que en él había de traducible. [...] Superfluo sería advertir que muchísimas expresiones del Diccionario se han pasado por alto, por ser simplemente intraducibles o por no tener importancia alguna para nuestro objeto" (1916: VIII). Con respecto a la bidireccionalidad, se podría decir que "sirve para poder entender en castellano lo que se diga en mapuche y para poder codificar en mapuche lo que se diga en castellano" (Gallardo 1986: 180). Por esto mismo, Gallardo (1986: 188) entiende este repertorio lexicográfico como un diccionario de uso; esto es, "dedicado primeramente a un hablante no nativo [de mapuzugun], culto pero sin instrucción lingüística, que tiene relación con la cultura [mapuche] y quiere aprender bien esta lengua".

\section{ALGUNAS CONCLUSIONES Y PROYECCIONES DE ESTE TRABAJO}

Pese a la producción y circulación de un número no despreciable de repertorios lexicográficos bilingües en esta época, y los diálogos entre las obras misionales y las de corte académico, lo cierto es que ya a principios del siglo XX, época en que se enmarcan estos trabajos, se retomó "la mediación de lenguaraces más que el intento de aprendizaje de la lengua, y en pocos años dejaron de ser necesarias ambas estrategias debido al proceso, de bilingüismo aditivo primero, y luego de sustitución de la lengua indígena, que tuvo lugar" (Malvestitti 2012: 80). Esto podría explicar la clara preponderancia de obras académicas en la época estudiada, obras que rescatan para la ciencia los últimos restos de una lengua que se condenaba a desaparecer, por sobre las obras misionales con su objetivo práctico-pedagógico, que precisamente decaen en el período estudiado.

A partir de esta primera aproximación al corpus, se puede ver que en el inicio del periodo las obras del corpus se concentran principalmente en 
Argentina: habrá que esperar hasta los primeros trabajos de Augusta (1903a) para encontrar repertorios lexicográficos bilingües a este lado de la cordillera; a partir de esta publicación, será en el lado occidental de la cordillera donde se publica la mayoría de los repertorios presentados en el corpus. De alguna manera, la distribución geográfica de la publicación de estas obras obedece a los distintos procesos políticos que dieron paso a la ocupación estatal de los territorios mapuche y sus propias temporalidades a uno y otro lado de la cordillera. Como una proyección de este primer trabajo, entonces, se plantea la necesidad de atender en detalle a los procesos políticos de ocupación y su relación con la producción de repertorios lexicográficos. De todas maneras, se puede plantear que en el periodo que va de 1800 a 1900 existe un declive en la producción misional, que se podría relacionar con los procesos de invasión militar de los estados argentino y chileno al territorio mapuche. Asimismo, en esta misma época, las publicaciones se concentran en el lado oriental de la cordillera, lo que de alguna forma podría explicar el público militar para el que se escribe en este territorio, punto que no se hace explícito en lado occidental. Esto de todas maneras señala una diferencia en el proceso militar de ocupación con respecto a los usos que pudo haber tenido la lengua en esos contextos.

Del mismo modo, aunque en este trabajo se señaló, habría que hacer un análisis exhaustivo de la nomenclatura que recibe la lengua mapuche para comprender a cabalidad la disputa metalingüística del nombre. Si bien es claro que en un principio obedece al proceso reduccional, es de notar que el término 'araucano' para referirse a la lengua mapuche es mucho más recurrente en las obras publicadas en Chile que en Argentina, lo que sin duda obedece a las características particulares del territorio en cuestión. De todas maneras, es necesario realizar una arqueología del nombre para comprender este desplazamiento. Por otra parte, esta primera aproximación al corpus permitió corroborar que las publicaciones misionales, que suelen ser en formato libro, se constituyen en su mayoría como una continua reformulación de Febrés. Las obras académicas, por su parte, aunque no comparten un hipertexto fundamental, sí tienen en común que la mayoría de las veces fueron publicadas como artículos de revistas y solo en algunos casos se publican como libros, a veces recopilando los artículos respectivos. Finalmente, aunque se consideró en este trabajo, es necesario desarrollar en detalle los usos que tiene la direccionalidad de la traducción en la lexicografía bilingüe del periodo. A partir del Anexo se puede ver que la dirección mapuzugun-español parece ser más frecuente en las publicaciones académicas y anticuarias; esto es, repertorios para decodificar el mapuzugun, que se contraponen al objetivo de producir y comunicarse en mapuzugun que predomina en las publicaciones misionales. 
De todas maneras, la situación colonial en la que se encontró el pueblo mapuche a partir de este periodo configura la asimetría fundamental entre hablantes y lenguas que pueden conocer, hablar y escribir sobre otros, y estos otros y sus lenguas que están destinados a ser conocidos, descubiertos y estudiados (Errington 2008: 55). En definitiva, ninguno de los repertorios lexicográficos revisados considera como su público al mapuche, sino que se escriben, principalmente, para poder hablarles, traducir instrumentos para su evangelización y gestionar su incorporación a las instituciones estatonacionales.

\section{REFERENCIAS BIBLIOGRÁFICAS}

\section{FUENTES PRIMARIAS}

Altschul, Nadia. (2012). Geographies of Philological Knowledge. Postcoloniality and the Transatlantic National Epic. Chicago \& London: The University of Chicago Press.

Augusta, Félix. 1903a. Gramática Araucana. Valdivia: Imprenta Central. 1916. Diccionario Araucano-Español, Español-Araucano. Santiago: Imprenta Universitaria.

BarbarÁ, Federico. 1879. Manual o Vocabulario de la lengua Pampay del Estilo Familiar. Para el uso de los jefes y oficiales del ejército, y de las familias a cuyo cargo están los indígenas. Buenos Aires: Imprenta y Librería de Mayo.

Cañas, Alejandro. 1911. Estudios de la lengua veliche. Santiago: Trabajos del IV Congreso Científico, T. IX: 143-330.

FEBRÉs, ANDRÉs. 1765. Arte de la Lengua General del Reyno de Chile, con un diálogo chilenohispano muy curioso, a que se añade La Doctrina Cristiana, esto es, Rezo, Catecismo, Coplas, Confesionario y Pláticas; lo más en Lengua Chilena y Castellana, y por fin un Vocabulario Hispano-Chileno, y un Calepino Chileno-Hispano más copioso. Lima: s/d.

Febrés, AndRÉs. 1846. Diccionario hispano-chileno (Enriquecido de voces i mejorado). Santiago: Imprenta del Progreso.

1882. Diccionario Araucano Español, o sea, Calepino chileno-hispano. Buenos Aires: Impreso por Juan Alsina. 1884. Gramática Araucana. Buenos Aires: Impreso por Juan Alsina.

Guzmán, Ignacio. (1998). Breve semblanza de las reediciones de obras lingüísticas. Antropología. Boletín Oficial del Instituto Nacional de Antropología e Historia 51: 42-49.

Havestadt, Bernhard. [1777] 1883. Chili-dugu sirve tractatus linguae chilensis. Leipzig: Edición de Julius Platzmann.

Milanesio, Domenico. 1900. Pequeño Diccionario de las voces que se hallan en este manual. Hecho por un Padre Salesiano, en Pablo Savino, Pequeño Manual del Misionero para evangelizar a los indios fronterizos. Buenos Aires: Imprenta de Pablo Coni.

1915. Etimología Araucana. Idiomas comparados de la Patagonia. Lecturas y frasario araucano. Buenos Aires: Talleres Gráficos del Estado Mayor del Ejército.

Outes, FéLIX. 1914. Un texto y un vocabulario en dialecto pehuenche de fines del siglo XVIII. Revista de la Universidad de Buenos Aires, T. 25: 68-73. 
SAvino, Pablo. [1876] 1900. Pequeño Manual del Misionero para evangelizar a los indios fronterizos. Buenos Aires: Imprenta de Pablo Coni.

SchÜller, Rodolfo. 1906-1907. El Vocabulario Araucano de 1642-1643. Con notas críticas i algunas adiciones a las bibliografías de la lengua mapuche. Anales de la Universidad de Chile, Tomo 119: 331-397, Tomo 120: 505-512 y Tomo 121: 251-330.

VaLdivia, Luis. [1606] 1887. Arte vocabulario y confesionario de la lengua de Chile. Leipzig: Edición de Julius Platzmann.

\section{Bibliografía SECUNDARIA}

Arnoux, Elvira. 2006. Análisis del discurso: modos de abordar materiales de archivo. Buenos Aires: Santiago Arcos.

y CARlos Luis. 2003. El Pensamiento Ilustrado y el Lenguaje. Buenos Aires: Eudeba.

Auroux, Sylvain. 1992. A revoluçao tecnológica da Gramatização. Campinas: Editora da UNICAMP.

Augusta, FéLIX. 1903b. Compendio de historia sagrada para uso de niños que frecuentan las escuelas católicas. Alemania: Friburgo de Brisgovia.

1910. Lecturas Araucanas. Valdivia: Imprenta de la Prefectura Apostólica.

Barros Arana, Diego y Rodolfo Lenz. 1893. La lingüistica Americana. Su historia i su Estado Actual. Santiago: Imprenta Cervantes.

Chen, Wenge. 2019. Towards a discourse approach to Critical Lexicography. International Journal of Lexicography 32 (3): 362-388.

Cifuentes, BÁRBARA. 2002. Lenguas para un pasado, huellas de una nación: los estudios sobre lenguas indígenas de México en el siglo XIX. México: Plaza y Valdés Editores.

Del ValLe, José. 2017. La perspectiva glotopolítica y la normatividad. Anuario de Glotopolitica 1: 17-39.

EngLERT, Sebastián. 1936. Lengua y Literatura Araucanas. Anales de la Facultad de Filosofía y Educación, Universidad de Chile, Tomo 1: 62-109.

ENNIS, JuAn ANTONIO. 2016. Rodolfo Lenz: economías de la lengua y políticas de la lingüística. Boletín de Filología 51 (1): 117-145.

Ennis, Juan y Stefan Pfänder. 2013. Lo criollo en cuestión: filología e historia. Buenos Aires: Ediciones Katatay.

ERrington, Joseph. 2008. Linguistics in a colonial world. A story of language, meaning, and power. Londres y Nueva York: Blackwell.

Foz, Clara y Gertrudis PayÀs. 2011. Las bibliografías hispanoamericanas coloniales y las Bibliotecas Americanas europeas como fuentes para la historia de la traducción. En Andrea Pagni, Gertrudis Payàs y Patricia Wilson (coords.). Traductores y traducciones en la historia cultural de América Latina, pp. 213-250. México D.F.: UNAM.

Gallardo, ANDRÉs. 1986. Fray Félix de Augusta y el Diccionario Araucano. Cultura, Hombre y Sociedad, Vol. 3 (1): 173-191.

HAENSCH, GÜNTHER. 1997. Los diccionarios del español en el umbral del siglo XXI. Salamanca: Ediciones Universidad de Salamanca.

Kornfeld, Laura e Inés Kuguel. 1997. Dos proyectos de integración del indígena a la nación argentina. La Gramática y diccionario de la lengua pampa, de Juan Manuel de Rosas (1825), y el Manual de la lengua pampa, de Federico Barbará (1879). Letterature d'America 59: 149-180.

Lara, Luis. 1996. Teoría del Diccionario Monolingue. México: El Colegio de México.

Lenz, Rodolfo. 1895-1897. Estudios araucanos. Santiago: Imprenta Cervantes. 
1917. Un diccionario araucano. Revista Chilena, Tomo II (7): 130-136.

MalvestitTi, Marisa. 2010. Lingüística misionera en Pampa y Patagonia (1860-1930). Revista argentina de historiografia lingüistica II (1): 55-73.

2012. Mediación lingüística al este de Los Andes en la época del awkan (fines del s. XIX). En Gertrudis Payàs y José M. Zavala. (eds.). La mediación lingüistico-cultural en tiempos de guerra: Cruce de miradas desde España y América, pp. 65-84. Temuco: Ediciones de la Universidad Católica de Temuco.

y María A. Nicoletti. 2011. Modalidades de evangelización a través de textos catequísticos bilingües en Araucanía, Pampa y Patagonia. En Pedro Navarro y Walter Delrio (eds.). Cultura y Espacio. Araucania-Norpatagonia, pp. 222-236. Bariloche: Universidad Nacional de Río Negro.

y Gertrudis Payàs. 2015. Circulaciones intertextuales del Arte de Febrés a ambos lados de los Andes. En María Nicoletti, Paula Núñez y Andrés Núñez (eds.). AraucaníaNorpatagonia III: Discursos y representaciones de la materialidad, pp. 282-303. Bariloche: Universidad Nacional de Río Negro.

Meirinho-Guede, Vitor, y José Del Valle. 2018. "Español” (y “castellano”). En Barbara Cassins. Vocabulario de las filosofias occidentales. Diccionario de los intraducibles, 2 vols., edición en español coordinada por Natalia Prunes y Guido Herzovich. México: Siglo XXI.

Molineaux, Benjamín. 2016. Vigencia del Diccionario Araucano de Félix de Augusta, a cien años de su publicación. Boletín de Filología, Tomo LI (1): 187-209.

Mora, Héctor y Mario SAMANiEgo. 2018. El pueblo mapuche en la pluma de los araucanistas. Seis estudios sobre construcción de la alteridad. Santiago: Ocho Libros.

y Rodrigo VÁzQuez (2018). La ciencia y lo "araucano" como ideas fuerza: Antropología y Emergencia del "Araucanismo" en Chile. En Mora, Hector y Mario Samaniego (eds.). El pueblo mapuche en la pluma de los araucanistas. Seis estudios sobre construcción de alteridad, pp. 22-87. Santiago: Ocho Libros

Nicoletti, María y Marisa Malvestitti. 2008. El uso de la lengua aborigen como práctica de evangelización: Domingo Milanesio y su prédica en mapuzungun (fines del siglo XIX y principios del siglo XX). Fronteras de la historia, Vol. 13 (1): 95-118.

Olimpio, María EugEnIA. 2009. Discurso metalexicográfico sobre los diccionarios bilingües, la equivalencia y la equivalencia fraseológica. En $\mathrm{M}^{\mathrm{a}}$ Teresa Fuentes y Benedikt Model (eds.). Investigaciones sobre lexicografia bilingüe, pp. 51-116. Granada: Ediciones Tragacanto.

PayÀs, GerTrudis. 2010. El revés del tapiz: Traducción y discurso de identidad en la Nueva España (1521-1821). Madrid/Frankfurt: Iberoamericana/Vervuert.

José Zavala y Mario Samaniego. 2012. Translation and interpretation on the Araucanian Frontier (seventeenth-nineteenth c.): an interdisciplinary view. Perspectives: Studies in Translatology, Vol 20, 4: 433-450.

Salas, Adalberto. 1985. Fray Félix José de Augusta. Su aporte a los estudios de la lengua y la cultura de los mapuches o araucanos. Cultura, Hombre y Sociedad, Vol. 2 (2): 197-272.

Smith, Edmond R. [1855] 1914. Los Araucanos o Notas sobre una gira efectuada entre las tribus indigenas de Chile. Santiago: Imprenta Universitaria.

Villena, BelÉn. 2017a. Fuentes de estudio para el mapudungún: Propuesta de periodización. Lenguas y Literaturas Indoamericanas, Vol 1 (19): 141-167.

2017b. Características del diccionario original. En Félix de Augusta [1916] 2017. Diccionario mapudungún-español y español-mapudungún, pp. XV-XIX. Temuco: Ediciones Universidad Católica de Temuco. 


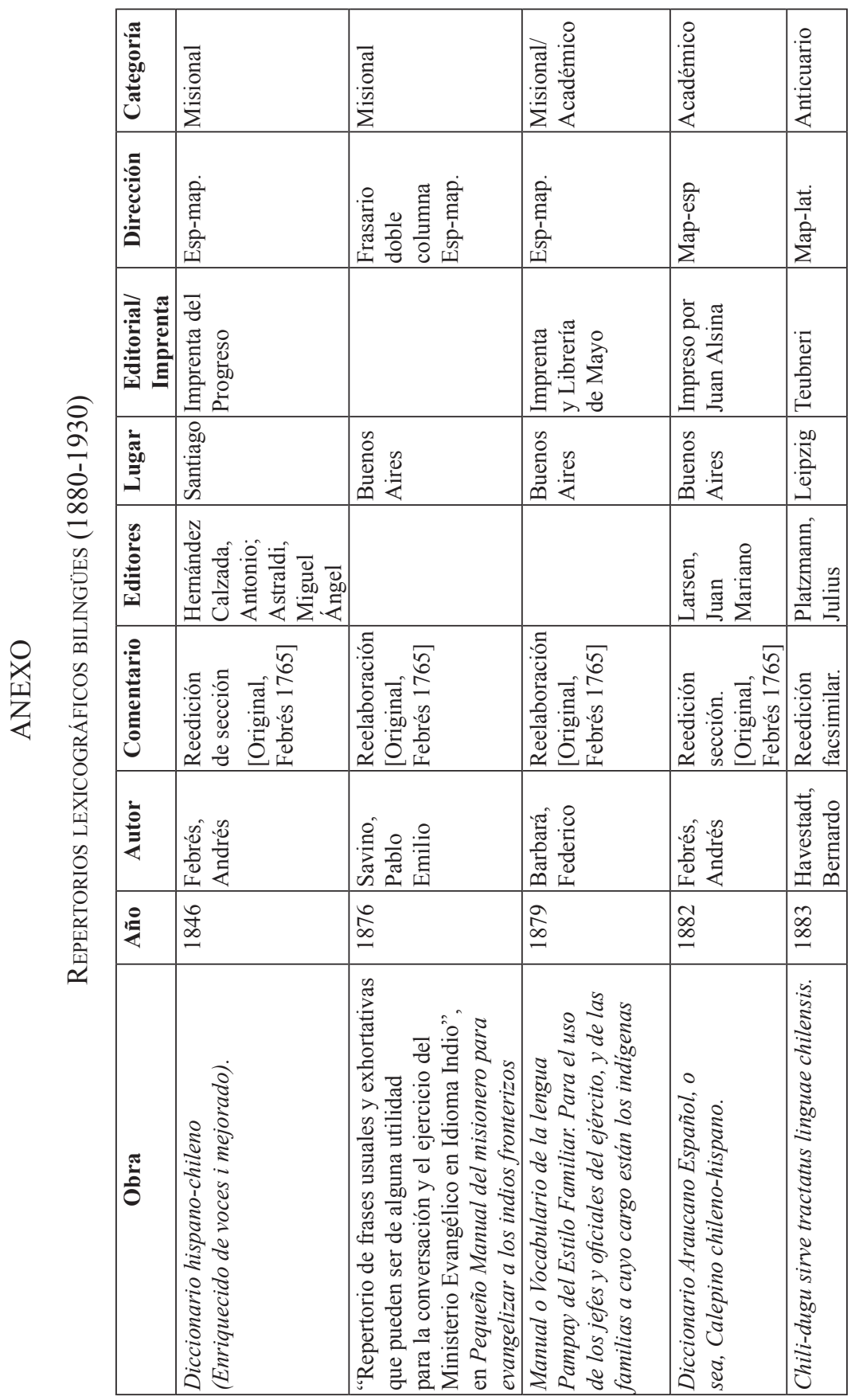




\begin{tabular}{|c|c|c|c|c|c|}
\hline .8. & .0. & 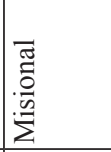 & 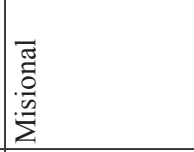 & 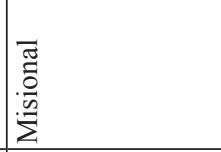 & . \\
\hline 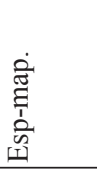 & 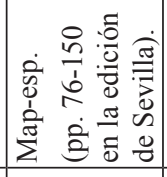 & 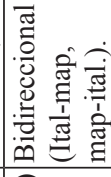 & & 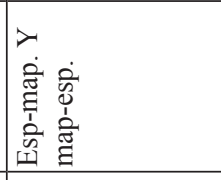 & 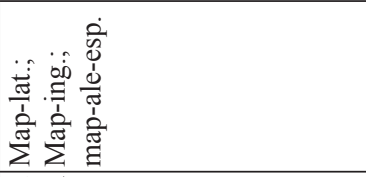 \\
\hline 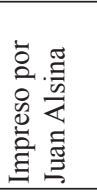 & 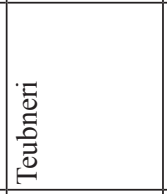 & 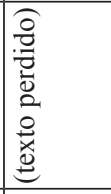 & 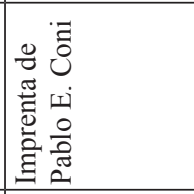 & 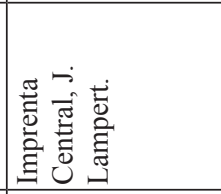 & 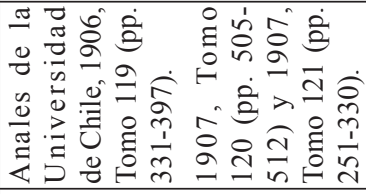 \\
\hline 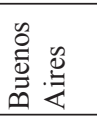 & 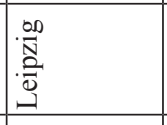 & & 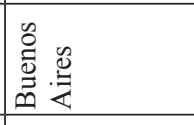 & 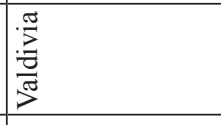 & 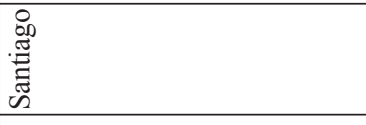 \\
\hline 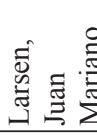 & 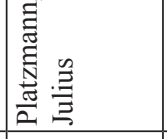 & & & & \\
\hline & 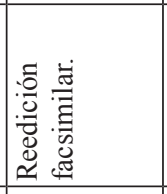 & 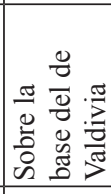 & 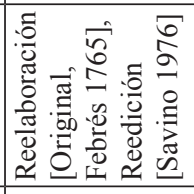 & & \\
\hline 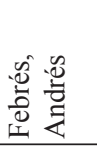 & 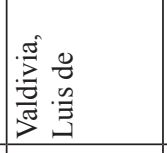 & 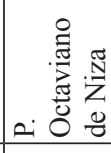 & 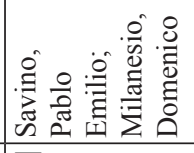 & 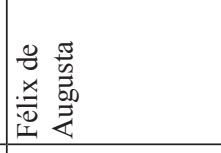 & 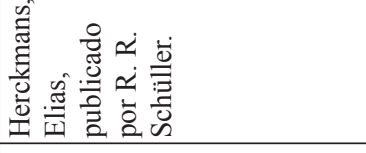 \\
\hline$\underset{\infty}{\mathbb{\infty}}$ & $\begin{array}{l}\infty \\
\infty \\
\infty\end{array}$ & $\begin{array}{l}\infty \\
\infty \\
\infty \\
-1\end{array}$ & 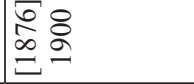 & ڤ̊ & ঠे \\
\hline 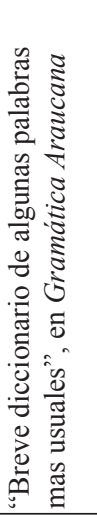 & 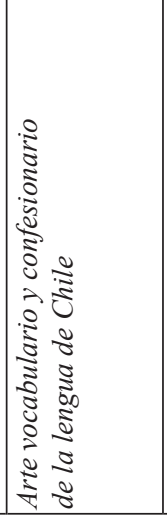 & 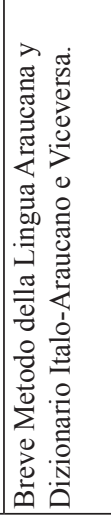 & 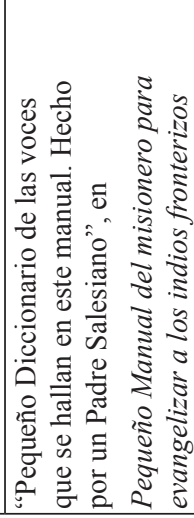 & 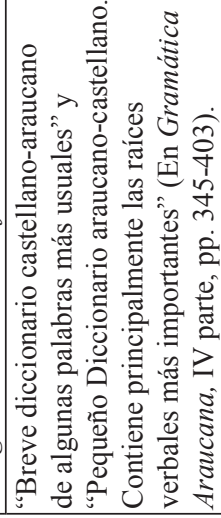 & 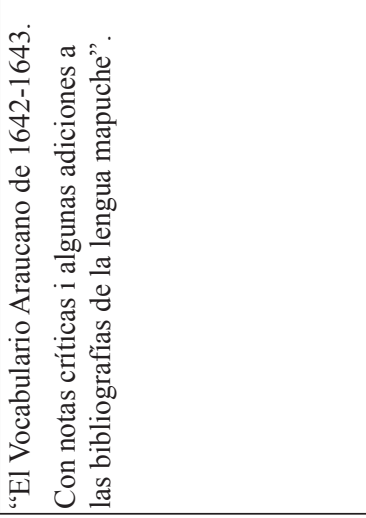 \\
\hline
\end{tabular}




\begin{tabular}{|c|c|c|c|c|}
\hline . & 号 & 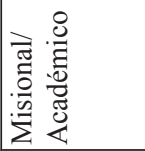 & & 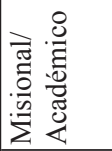 \\
\hline 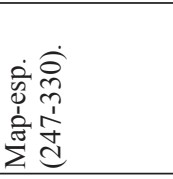 & 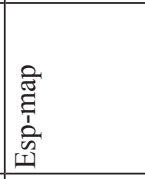 & & & 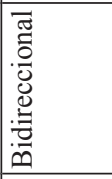 \\
\hline 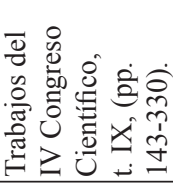 & 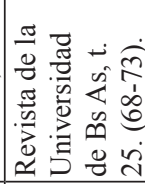 & 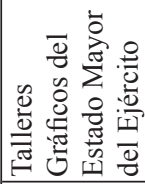 & & 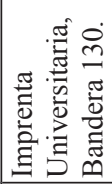 \\
\hline : & & 告 & 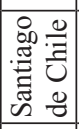 & 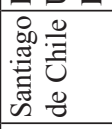 \\
\hline & & 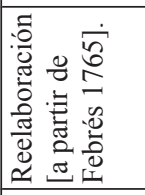 & & \\
\hline 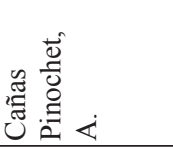 & 岕 & 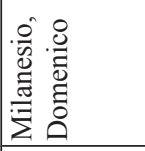 & 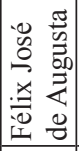 & 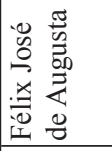 \\
\hline $\bar{\sigma}$ & $\frac{\Xi}{2}$ & $\frac{n}{2}$ & $\frac{0}{2}$ & \\
\hline 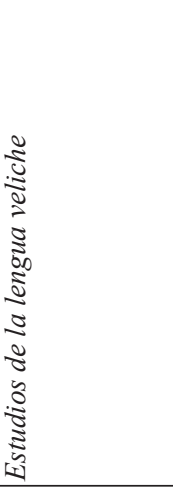 & 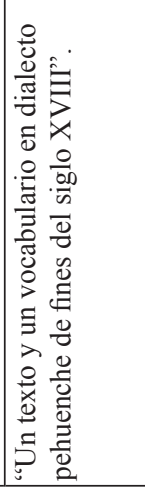 & 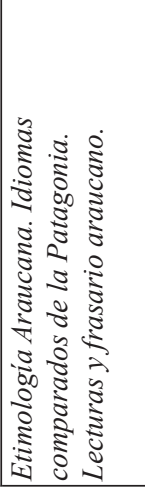 & 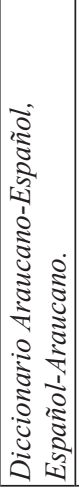 & \\
\hline
\end{tabular}

